\title{
MUSIK TERAPI DALAM PERSPEKTIF BUDAYA
}

\section{Dahlan Taher}

\section{FBS Universitas Negeri Yogyakarta}

\section{Abstract}

Classical music is said to have healing power. However, whether it can be used universally as common medicines remains questionable. The fact shows how music perceived by human senses is the same among people of different cultures. On the other hand, since music is a product of culture, human different cultures. On the other hand, since music is a product of culture, human
perception of music might also vary according to their cultures. Some people

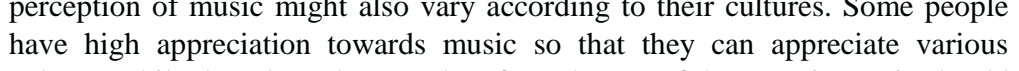
cultures while the others do not. Therefore, the use of therapeutic music should be in accordance with someone's sense of appreciation towards it so that the therapy can give better effects.

Keywords: classical music, therapy, culture

\section{A. Pendahuluan}

Publikasi besar-besaran hasil penelitian Alfred Tomatis, seorang dokter, psikolog, dan tokoh pendidikan dari Perancis, yang menyatakan bahwa musik klasik, terutama musik-musik karya Wofgang Amedeus Mozart, dapat membuat bayi-bayi yang mendengarkan musik tersebut menjadi cerdas. Penelitian Tomatis dikuatkan dengan diterbitkan buku yang berjudul 'Efek Mozart' karangan Don Campbell. Buku tersebut memuat penelitian Frances Rauscher, Gordon Shaw, dan koleganya yang semakin menguatkan pernyataan bahwa musik Mozart, yang kemudian dikenal sebagai Efek Mozart, dapat mencerdaskan dan juga dapat digunakan sebagai terapi. Beberapa tulisan di media massa seperti Science Times: The Mystery of Music. How It Work to The Brain, Your Child Brain : How Kids are Wired for Music, dan Learning Music: Exercise for The Brain, Does Music Make Babies Smart?, juga membawa orang beramai-ramai mendengarkan musik-musik klasik. Media massa di Indonesia seolah-olah tidak mau ketinggalan untuk menulis tentang pengaruh musik pada kecerdasan anak. Salah satu artikel tersebut terdapat pada Intisari bulan Mei 1999 yang berjudul 'Anak Cerdas dan Kreatif Berkat Alunan Musik' tulisan I Gede Agung Yudana. Selain untuk mencerdaskan bayi, musik klasik dapat pula digunakan sebagai terapi untuk bayi yang lahir prematur, penyakit Parkinson, pereda nyeri, gangguan perkembangan dan psiko-sosial, luka bakar, dan lain sebagainya.

\section{B. Pengertian Musik Klasik}

Timbul pertanyaan, sekuat itukah pengaruh musik-musik klasik, terutama musik-musik Mozart? Bagaimana dengan musik-musik lainnya? Apakah musik- 
musik klasik tersebut, yang berasal dari budaya Eropa, dapat diterapkan secara universal ataukah ada deviasi budaya?

Untuk menjawab pertanyaan-pertanyaan tersebut perlu diketahui makna dari musik klasik itu terlebih dahulu. Menurut The New Harvard Dictionary of Music, klasik berasal dari bahasa Latin, classicus, yaitu penduduk Roma yang berasal dari golongan tertinggi. Sedangkan klasik sendiri memiliki tiga makna, yaitu :

1) dalam pengunaan yang populer, berarti musik seni atau musik 'serius' yang merupakan lawan dari musik 'populer'

2) dalam literatur Perancis tentang musik, merujuk pada periode atau gaya $\mathrm{d}$ masa raja Louis XIV (1643-1715), yang diperluas untuk menyebut karya komponis Jean-Phillipe Rameau (1683-1764).

3) periode atau gaya yang berasal dari Italia mulai dari awal abad 18 sampa awal abad 19.

Klasik menurut pengertian yang terakhir adalah periode waktu tertentu yang memiliki gaya seni yang berbeda dengan periode sebelum, Barok, dan sesudahnya, Romantik, baik dalam seni rupa, seni sastra, arsitektur, dan seni musik Definisi klasik yang pertama dan terakhir seringkali terjadi salah kaprah dalam penggunaannya, karena karya-karya seni dari periode Barok dan Romantik dapat juga didefinisikan sebagai karya klasik, sesuai dengan definisi pertama di atas. Oleh karena itu dalam tulisan ini penggunaan istilah 'musik klasik' digunakan dalam konteks yang populer sesuai dengan definisi pertama dan istilah 'musik Klasik' (dengan huruf kapital) digunakan untuk merujuk pada musik dari periode Klasik, sama dengan penggunaan istilah musik Romantik atau musik Barok.

Seni pada periode Klasik mengungkapkan perasaan dan sikap manusia secara obyektif serta diimbangi dengan pandangan yang holistik, sehingga musik Klasik berusaha menciptakan bahasa universal yang dimengerti tidak hanya secara lokal tetapi secara internasional. Oleh karena itu, musik Klasik kebanyakan merupakan karya-karya yang instrumental dan tanpa syair.

Dalam lingkungan seperti itulah Mozart (1758-1791) hidup. Semasa hidupnya Mozart adalah anak yang jenius dan pada umur 5 tahun ia sudah dapa memainkan piano serta membuat komposisi yang sederhana. Karena kejeniusannya, ayahnya mengajaknya konser keliling Eropa. Falsafah Klasik membuat musik Mozart dapat diterima di seluruh dunia, yang pada masa tersebut hanya mencakup seluruh Eropa, Turki dan sekitarnya, serta bagian barat Rusia.

Dari penjelasan di atas, falsasah musik Klasik berarti terapi dengan musik Klasik, terutama musik Mozart, dapat diterapkan pada siapapun tanpa perlu memperhitungkan adanya bias budaya. Mozart yang karena kejeniusannya disebut sebagai anak ajaib, lewat karya-karyanya dapat 'memindahkan' kecerdasannya

Imaji, Vol.4, No.1, Februari 2006: 53 - 60 kepada bayi-bayi pada masa kini meski berasal dari berbagai latar belakang budaya. Meskipun musik Mozart dapat diterima diseluruh dunia pada masanya, namun istilah seluruh dunia pada masa itu cuma sebagian kecil dari dunia pada masa sekarang. Muncul pertanyaan antara lain dapatkah musik Mozart diterapkan pada masa kini mengingat pengertian tentang dunia yang sempit pada masa tersebut? Bagaimana dengan musik klasik lainnya?

C. Definisi Musik Terapi

Djohan (2003) mendefinisikan musik terapi adalah penggunaan musik sebagai terapis untuk memperbaiki, memelihara, mengembangkang mental, fisik, dan kesehatan emosi. Terapi musik digunakan untuk memperbaiki kesehatan fisik, interaksi sosial, mengembangkan hubungan interpersonal, mengekpresikan emosi secara alamiah, dan meningkatkan kesadaran diri. Kemampuan non verbal, kreatifitas, dan rasa alami musik menjadi fasilitator untuk mencapai tujuan tersebut.

Wigram (2000) mendefinisikan musik terapi sebagai penggunaan musik secara klinikal, edukasional, dan situasi sosial untuk memperlakukan (treat) klien atau pasien dengan keperluan medikal, edukasional, sosial, atau psikologi. Sementara itu, World Federation of Music Therapy (1996) mendefinisikan musik terapi sebagai berikut :

Music therapy is the use of music and/or musical elements (sound, rhythm, melody, and harmony) by a qualified music therapist with a client or group, in a process designed to facilitate and promoted communication, relationships, learning, mobilisation [sic], expresision, emotional, mental, social, and cognitive needs. Music therapy aims to develop potentials and/or restore functions of the individual so that he or she can achieve better intra- and inter-personal intergation and, consequently, a better quality life through prevention, rehabilitation or treatment.

Di Amerika, untuk menjadi seorang terapis musik, seseorang haruslah lulusan sarjana dibidang musik terapi yang diakreditasi American Music Therapy Association. Lulusan tersebut haruslah memiliki ketrampilan bermain instrumen musik, berpengetahuan tentang teori, sejarah, dan komposisi musik, serta dilengkapi pengetahuan dibidang psikologi, sosiologi, anatomi, dan fisiologi. Selain itu, ia harus mejalani program profesi selama 6 bulan dan ia harus memiliki rasa percaya diri, sadar diri, dan memiliki persepsi realitis terhadap kelemahan dan kelebihan yang dimilikinya. Seorang terapis musik harus memiliki cara berpikir kreatif, spontan, energik, fleksibel, dan rasa humor.

D. Latar Belakang Sejarah

Penggunaan musik sebagai media terapi sudah banyak dilakukan pada masa dimana psikologi, kedokteran, dan musik masih bernaung pada induk 
pengetahuan yaitu filsafat. Menurut Horden (2000), musik terapi sudah dimulai pada masa Hippocrates yang menulis risalah tentang doktin metafisik musik jauh sebelum adanya tulisan tentang pengobatan. Pythagoras yang melakukan eksperimen dengan dawai yang dibagi dalam rasio perbandingan tertentu, menemukan nada-nada yang kita kenal sekarang. Menurut Pythagoras, nadanada dan jarak antara nada satu ke nada lainnya merupakan refleksi dari kosmik dalam tingkatan spiritual. Getaran yang ditimbulkan dawai yang menghasilkan nada yang ditangkap oleh indera dapat mempengaruhi seseorang karena tubuh (body), pikiran (mind) dan jiwa (spirit) adalah satu kesatuan.

Pemikiran Pythagoras tersebut dikembangkan oleh Plato dalam bukunya The State yang menjelaskan bagaimana musik dapat mempengaruhi pikiran manusia. Socrates pun menyebutkan bahwa susunan nada-nada tertentu dapat mengarahkan seseorang untuk hidup harmonis dan berani, sedangkan susunan nada-nada lainnya dapat mengurangi kesedihan. Marcillio Ficino (1433-1499) yang mengabungkan doktrin Plato dengan dogma Kristen, menyatakan bahwa jiwa (soul) adalah penyeimbang antara tubuh dan pikiran. Musik membantu jiwa untuk mencapai kesimbangan tersebut. Pada era moderen sekarang ini, elemen yang spekulatif dan metafisik telah digantikan dengan pemikiran yang ilmiah dan data-data empiris.

Dalam beberapa budaya juga telah ditemukan penggunaan musik dan suara (sound) sebagai terapi dan ritual penyembuhan (Gouk, 2000). Dalam budaya yang primitif, praktek shamanisme adalah salah satu contohnya. Mitologi dan cerita tentang kekuatan musik sebagai alat penyembuh juga hadir dalam beberapa budaya, Orpheus adalah salah-satu contoh mitologi tersebut.

Di Amerika, penggunaan musik sebagai terapi berkembang pada masa Perang Dunia I. Musik diputarkan di rumah sakit untuk veteran perang untuk menyembuhkan trauma perang. Pasien dilibatkan secara aktif maupun pasif dalam terapi tersebut. Hasil positif menyebabkan lembaga pendidikan dan akademi mengembangkan program pelatihan kepada para musisi untuk menggunakan musik sebagai terapi. Lalu berdiri organisasi musik terapi di Amerika yaitu National Association for Music Therapy, yang lalu melebur menjadi American Music Therapy Association.

Penelitian penggunaan musik tidak hanya kepada manusia saja akan tetapi juga pada hewan dan tumbuhan. Para biarawati di Brittany memainkan musik pada hewan peliharaannya dan menemukan bahwa sapi-sapi menghasilkan susu lebih banyak. Perusahaan minuman Ohara di Jepang utara menggunakan musik untuk menaikkan kualitas sake yang diproduksinya. Simfoni nomor 6 dari Beethoven yang diputarkan sambil menunggu roti mengembang, merupakan bagian dari resep dari sebuah perusahaan roti di Nagoya.

Imaji, Vol.4, No.1, Februari $2006: 53$ - 60
Jelas bahwa penggunaan musik sebagai alat terapi sudah ada, jauh sebelum Efek Mozart dipublikasikan. Musik terapi sudah ada pada masa dimana hanya ada satu ilmu yaitu filsafat dan dewasa ini, musik terapi menjadi bagian dari ilmu kedokteran, psikologi, dan musik sendiri. Beberapa budaya bahkan memiliki tradisi musik terapi yang serupa dengan konsep metafisik musik terapi barat pada awalnya.

\section{E. Musik Merupakan Bahasa Universal}

Kita dapat mengoyangkan tubuh mengikuti lagu Copa de la Vida yang menghentak, atau menyenandungkan suatu lagu daerah tanpa tahu arti syair dari lagu tersebut. Tari Poco-Poco dari Maluku dapat ditarikan dengan riang hampir seluruh penduduk Indonesia. Itu menunjukkan bahwa musik itu bersifat universal.

Auh Myong-sook (2002) meneliti tentang alasan mahasiswa Amerika, Korea, dan Australia dalam menyenangi musik-musik tertentu. Alasan menyenangi musik tersebut dibagi atas 3 alasan yaitu (1) alasan personal/ emosional, (2) alasan musikal, dan (3) alasan sosial. Ditemukan bahwa dari ketiga negara tersebut tidak ada perbedaan yang signifikan untuk alasan menyenangi musik. Juga tidak ada perbedaan yang signifikan antara pria dan wanita dari ketiga negara tersebut dalam menyenangi musik. Pada ketiga negara, alasan personal/emosional secara signifikan lebih tinggi dari alasan musikal dan dari alasan sosial.

Perbedaan yang ditemukan dalam penelitian tersebut adalah bahwa alasan mahasiswa Korea lebih bersifat personal/emosional dari mahasiswa Ausralia. Ini disebabkan oleh gaya pembelajaran musik di Korea yang lebih menitik-beratkan pada gaya berbagai macam musik (aspek afektif) dibandingkan pada konsep tentang musik itu sendiri (aspek kognitif).

Trevarthen et al (2002) menyatakan bahwa rasa musikal seseorang berakar kuat secara biologis. Bayi dapat merespon dan mencoba mengimitasi bunyi dan suara disekelilingnya. Dengan cara tersebut pula bayi membentuk identitas musikalnya (musical identity). Pada usia antara 2 sampai 6 bulan, bayi memfokuskan perhatiannya dalam membagi pengalaman subyektifnya dengan benda hidup, dalam hal ini, orang-tua sang bayi. Riset menunjukkan bahwa komunikasi awal mula komunikasi ditunjukkan dengan ritme suara, menjalin pengalaman subyektif antara ibu dan bayinya. Berbagi pengalaman seperti itulah adalah cikal bakal perasaan musikal terhadap pulsasi ritme yang teratur dan ekspresi musikal. Dengan cara itu pula, bayi menemukan identitas dirinya. Pada ibu imigran Indian di Amerika yang stres dan bingung dengan budaya yang baru, bayi mereka pun kurang dapat mengekpresikan pulsasi ritme.

Penelitian Demorest et al (2002) menunjukkan pula bahwa, secara biologis, tidak ada bias budaya dalam mendengarkan musik. Jadi, pada dasarnya 
tiap individu sama dalam mempersepsikan musik. Pada penelitiannya, Demorest et al memakai subyek 6 orang western-trained musician dan 6 orang yang bukan musisi untuk mendengarkan musik Barat dan musik tradisional Cina. Dalam pantauan fMRI, ditemukan tidak ada perbedaan signifikan antara musik Barat dan musik tradisional Cina diantara keseluruhan subyek.

\section{F. Musik Merupakan Produk Budaya}

Budaya adalah bagian dari lingkungan yang diciptakan dan dibentuk oleh manusia (Herskovits, 1948). Menurut Walker (2002), musik adalah produk dari kepercayaan (beliefs), teknologi, kebiasaan sosial (social habits), dan psikologi dari budaya tertentu (psychology of a particular culture). Dari definisi di atas jelas terlihat bahwa musik merupakan hasil dari budaya dan tidak bisa lepas dari budaya.

Pada suku Inuit di daerah Artik, Kanada, mempunyai teknik menyanyi dengan menghembuskan dan menarik nafas. Para gembala di pegunungan Alpen mengembangkan teknik yodel dalam menyanyi dimana nyanyian tersebut sahut menyahut dengan gembala lainnya yang letaknya saling berjauhan. Teknik yodel tersebut berbeda dengan yang dipraktekkan suku Pygmi. Banyak budaya di Asia, termasuk budaya Jawa, yang menyanyi lewat pangkal tenggorokan, sehingga menimbulkan suara seolah-olah keluar dari hidung. Teknik bernyanyi ini jelas berbeda dengan teknik menyanyi opera di musik klasik.

Dalam musik tradisional Jepang, menurut Murao (2002), keaslian tidaklah penting. Yang penting adalah unsur holistik dalam musik dan keyakinan dalam mengimitasi sang guru, terutama dalam proses pembelajaran musik. Dengan mengimitasi sang guru, dasar musik dan gaya dalam mempertunjukkan musik dapat disamakan. Gaya individual akan muncul sendiri sesuai dengan kepribadian dari sang murid. Ini menyebabkan tidak ada istilah 'kreatif' dalam musik tradisional Jepang, khususnya dalam hal pembelajaran.

Rawlings et al (2002) melakukan penelitian apakah ada hubungan antara 5 tipe kepribadian (sensation seeking, openness, psychoticism, extraversion, dan neuroticism) dengan pemilihan 4 jenis nuansa lagu (riang, sedih, tenang, dan tense). Apakah dalam melakukan pemilihan 4 jenis nuansa lagu tersebut, ada perbedaan antara subyek di Australia, Spanyol, dan Israel? Di Australia, ditemukan bahwa kepribadian sensation seeking, openness, dan psychoticism tidak menyenangi musik yang tenang (calm). Di Spanyol ditemukan bahwa kepribadian sensation seeking, openness, dan psychoticism ditambah dengan kepribadian yang extraversion menyenangi musik yang memiliki nuansa keras (tense). Namun pada sampel Israel, tidak ditemukan korelasi yang signifikan antara kepribadian seseorang dengan nuansa musik tertentu. Dapat diterangkan bahwa Australia dan Spanyol memiliki latar kebudayaan yang hampir serupa yaitu latar belakang budaya Eropa. Meskipun Australia adalah benua yang terletak jauh dari Eropa, namun sebagian besar penduduknya adalah pendatang dari Eropa. Selain itu, subyek penelitian adalah mahasiswa dan tidak dijelaskan dalam jurnal apakah ada subyek dari penduduk asli Australia, yaitu orang Aborigin. Israel memiliki latar budaya yang berbeda dengan negara Australia dan Spanyol, oleh karena itu tentulah tidak didapatkan korelasi yang juga ditemukan di Australia ataupun Spanyol. Konstruk tentang kepribadian atau tentang nuansa musik yang diteliti mungkin tidak sesuai dengan keadaan orang-orang Israel.

Dalam masyarakat Jawa, memainkan musik (dalam hal ini, gamelan) merupakan salah satu sarana untuk berkumpul dan bersosialisasi, serta hiburan. Oleh karena itu, ketrampilan memainkan gamelan tidak perlu tinggi, yang terpenting adalah mewujudkan falsafah, mangan ora mangan, kumpul (makan atau tidak, kumpul). Ini sesuai dengan pernyataan Senyshyn (2002) yang menyatakan perlunya subyektifitas filosofi yang tercermin dalam konstruk diri seseorang.

Robert Walker (2002) menyatakan bahwa budaya merupakan pengerak sesungguhnya akan persepsi seseorang terhadap musik dan pernyataan tersebut tercermin dalam tulisannya yang berjudul Culture is The Real Driver in Music Perception. Sebagai contoh, seorang ibu bertanya, "lagunya mana?" setelah mendengarkan sebuah lagu jazz, yang dimainkan secara instrumentalia, pada suatu pementasan di lokasi KKN. Bagi ibu tersebut sebuah lagu haruslah bersyair dan persepsi tersebut dibentuk oleh latar belakang budaya sang ibu.

\section{G. Penutup}

Musik adalah sebuah bahasa yang universal sehingga dapat diterima secara universal, namun musik merupakan produk budaya yang tidak lepas dari bias budaya. Bias ini terjadi bisa disebabkan oleh falsafah terutama falsafah seni yang beragam dari latar belakang budaya yang beragam pula. Dalam melakukan penelitian dalam psikologi yang melibatkan musik sebagai variabel, perlu memperhatikan bagaimana persepsi subyek terhadap musik yang akan digunakan dalam penelitian. Sudahkah musik tersebut dipersepsikan secara universal oleh subyek ataukah latar belakang budaya subyek akan menyebabkan penelitian tersebut menjadi bias.

Adanya bias budaya tersebut juga mempengaruhi persepsi seseorang terhadap musik-musik tertentu. Dalam menerapkan hasil penelitian, terutama dalam penggunaan musik sebagai terapi, perlu melihat latar-belakang klien dalam mengapresiasi musik. Latar-belakang tersebut merupakan acuan dalam menentukan jenis musik yang akan digunakan dalam terapi. Penelitian lintas budaya, terutama musik-musik nusantara, dalam bidang musik terapi sehingga penerapan musik terapi di Indonesia tidak semata-mata hanya menerapkan hasil penelitian yang berbeda kebudayaannya dengan bangsa kita. 


\section{DAFTAR PUSTAKA}

Auh, Myung-sook, 2002 : "Reasons for Liking Music : Differences by Country and Gender Among Australian, Korean, and American University Students", 7. International Conference in Music Perception and Cognition, Sidney.

Berry, John W. et.al. 1992 : Cross-Cultural Psychology : Research and Applications. Cambridge : Cambridge University Press.

Campbell, Don, 2001: Efek Mozart, Jakarta, Gramedia

Demorest, Steven M. et.al.2002 : An fMRI Study of Cross-Cultural Music Comprehension, $7^{\text {th }}$ International Conference in Music Perception and Cognition, Sidney.

Djohan 2003 : Psikologi Musik. Yogyakarta : Buku Baik

Murao, Tadahiro. 2002 : What is Creativity in Japanese Traditional Music, 7 International Conference in Music Perception and Cognition, Sidney.

Prier, Karl-Emund. 1993 : Sejarah Musik jilid 2. Yogyakarta : Pusat Musik Liturgi.

Rawlings, David., Ziv, Naomi., Hill, Mechaela., \& Barrantes-Vidal, Neus. 2002 : Personality and Liking Music Excerpts Categorised According to 'Mood Quality': A Cross-Cultural Study, $7^{\text {th }}$ International Conference in Music Perception and Cognition, Sidney.

Randel, Don. 1986 : The New Harvard Dictionary of Music. London : The Belknap Press of Harvard University Press.

Senyshyn, Yaroslav. 2002 : A Philoshopical Approach to Music and Performance Vis-À-Vis Discursive Psychology, Social Contruction, Perception and Preference, $7^{\text {th }}$ International Conference in Music Perception and Cognition, Sidney.

Trevarthen, Colwyn. Gratier, Maya. \& Malloch, Stephen. 2002 : Origins of Musical Identity : Evidence from Infancy, $7^{\text {th }}$ International Conference in Music Perception and Cognition, Sidney.

Walker, Robert. 2002 : Culture is The Real Driver in Music Perception, 7 International Conference in Music Perception and Cognition, Sidney.

Wigram, Tony., Pedersen, Inge Nygaard., \& Bonde, Lars Ole. 2002 : A Compehensive Guide to Music Therapy: Theory, Clinical Practice Research and Training. London : Jessica Kingsley Publisher Ltd. 